\title{
The myth of informed consent: in daily practice and in clinical trials
}

\author{
William A Silverman Greenbrae, California
}

\section{Author's abstract}

Until about thirty years ago, the extent of disclosure about and consent-seeking for medical interventions was influenced by a beneficence model of professional behaviour. Informed consent shifted attention to a duty to respect the autonomy of patients. The new requirement arrived on the American scene in two separate contexts: for daily practice in 1957, and for clinical study in 1966. A confusing double standard has been established. 'Daily consent is reviewed, if at all, only in retrospect. Doctors are merely exhorted to obtain informed consent; they often minimise uncertainties about 'best' treatment and they feel duty-bound to provide patients with an unequivocal recommendation for action. 'Study consent' in a clinical trial is reviewed prospectively, and doctors are compelled by regulation to point out that there is insufficient evidence to make a rational choice between two compared treatments. It has been impossible to devise informed consent practices that satisfy, in full, the competing moral imperatives of respect for autonomy, concern for beneficence with emphasis on the value of health, and a vigil for justice. A way must be found to experiment with various discretionary approaches that would strike a realistic balance among competing interests.

Truth-telling and consent-seeking for specific interventions (particularly surgical invasion) have long been a part of medical tradition (1). Moreover, the patient's right of prior consent has long been protected in many countries under laws of assault and battery. But the doctrine, until relatively recently, was narrowly defined. Doctors were obliged only to disclose the nature of a proposed procedure; the patient reserved the right of refusal. In 1767, for example, a British judge noted that 'a patient should be told what is about to be done to him, that he may take courage and put himself in such a situation as to enable him to undergo the operation' (2). Following the disclosure, a patient 'voted with his/her feet': voluntary submission was taken as proof of consent.

\section{Key words}

Informed consent; clinical trials; patients' autonomy; beneficence; justice; medical practice; hedging strategy (in clinical study).

\section{Domination of beneficence}

Until about thirty years ago, the extent of disclosure and consent-seeking was very much influenced by a beneficence model of professional behaviour. A physician's primary obligation (surpassing respect for patient autonomy), it was held, is to provide medical benefits. In 1803, Thomas Percival noted that the first role of the physician is to be 'the minister of hope and comfort'. And he asked: 'How far is it justifiable to violate truth for the supposed benefit of the patient?' He concluded that 'the balance of truthfulness yields to beneficence in critical situations' (3). The physician does not actually lie in actions of deception and falsehood, Percival argued, as long as the objective is to give hope to the dejected or sick patient. Since there was no appreciable dissent from this view, the beneficence model, roughly as outlined by Percival, served, widely and apparently well, as a guide to doctors when they interpreted their responsibility to patients (4).

\section{Informed consent in daily practice}

Informed consent is a modern American invention. The new principle shifted attention to a physician's duty to respect the autonomy of patients. As I have noted elsewhere, it arrived on the medical scene in the context of daily practice (5).

\section{THE SALGO DECISION}

The pregnant phrase was first used in 1957 by Justice Bray of the California Court of Appeals in the legal controversy of Salgo v Stanford University (6). (Martin Salgo suffered permanent paralysis following diagnostic translumbar aortography. He complained that his physicians were negligent in carrying out the procedure and that they failed to inform him of the risk of paralysis.) The court (using words suggested by the American College of Surgeons in a friend-of-the-court brief (7)) concluded that Salgo's doctors had a duty to disclose 'any facts which are necessary to form the basis of an intelligent consent by the patient to the proposed treatment'. Justice Bray went on to indicate that this new duty to disclose risks and alternatives of treatment was a logical extension of the already established obligation to reveal a treatment's nature and its consequences. 'In discussing the element of risk', Bray wrote, 'a certain amount of discretion must be 
employed consistent with full disclosure of facts necessary to an informed consent' [emphasis added].

\section{A NEW STANDARD}

Legal scholars have pointed out that the Salgo decision introduced distinctly new elements into the relationship of trust between doctors and their patients (4). Unlike previous opinions about consent to medical treatment, the Salgo court focused on the problem of whether or not the consent had been informed when given. The court created an 'informed consent' standard: the nature, consequences, harm and benefits, risks and alternatives of a treatment on offer were now held to be the information needed by a patient in order to know what he/she is choosing.

The relatively new doctrine of informed consent, in the daily routines of the doctor-patient relationship, has achieved high social visibility and has been discussed widely. Nonetheless, there is surprisingly little evidence of meaningful implementation.

\section{PRACTICAL CONSEQUENCES}

The Salgo court's words, and subsequent legal decisions, have not changed the time-honoured 'silent world' of doctor and patient in a realistic way (7). For example, surveys in the United States give the impression that informed consent is routinely sought in daily medical practice. In 1982, among 805 physicians surveyed almost all indicated that they obtained written consent ( 80 per cent) or both written and oral consent ( 15 per cent) before inpatient surgery or the administration of anaesthesia (8). However, responses obtained in this survey suggest that most of the doctors recognised only the information-giving aspect of informed consent. Few of the respondents ( 9 per cent) seemed to be aware that the consentseeking routine was intended to allow patients to make a choice or to state a preference about the treatment on offer. There is, in fact, no credible evidence about the extent to which the rituals of consent-seeking carried out in daily practice satisfy three reasonable criteria proposed by Faden and Beauchamp (4).

1. A patient must agree to an intervention based on an understanding of (usually disclosed) relevant information,

2. Consent must not be controlled by influences that would engineer the outcome,

3. The consent must involve the intentional giving of permission for an intervention.

\section{ROLE OF LEGISLATION AND THE COURTS}

Following the Salgo decision, the dimensions of the requirement for informed consent for everyday procedures were slowly shaped in the United States by case law (that is to say, in judicial opinions concerning specific law suits, and, later, as defined in statutes). However, the legal 'life' of the doctrine, has not been very robust. Everyday consent, it should be noted, is reviewed, if at all, only in retrospect (for example, at the time of a law suit for malpractice). Katz has observed that judges in the United States have toyed $\stackrel{\text { I }}{=}$ briefly with the idea of patients' right to selfdetermination (7). For the most part, however, jurists have not been supportive. 'The law of informed $\stackrel{\vec{P}}{\rightarrow}$ consent,' Katz opines, 'is fairy-tale like'. In the 'implementation of dicta it conveys a mythic pessimism of human capacities to be choice makers'.

\section{Informed consent in clinical trials}

Nine years after Salgo, informed consent was spelled ڤึ out as a requirement in American guidelines for clinical $\vec{\circ}$ research. In February 1966, a memorandum entitled $\rightarrow$ Clinical Investigations Using Human Subjects was $\vec{\omega}$ circulated by the Surgeon General (9). For the first time, clinical studies using federal funds were required to institute prior review which was to include the $\vec{r}$ appropriateness of methods to secure informed $\stackrel{G}{-}$ consent'.

\section{A PARADOXICAL DUALITY}

The new ruling made it clear that study-consent was to be considered quite separately from daily-consent. The major difference turned on the issue of candour about $\stackrel{\bar{S}}{\Im}$ current evidence. When obtaining study-consent in $\mathrm{a}-\vec{P}$ treatment trial, for example, a doctor was now required $\stackrel{\oplus}{\oplus}$ to disclose the justification for the trial by pointing out ${ }^{\circ}$ that there was insufficient existing information for both doctor and patient to make a rational, informed choice about the most effective treatment. In daily-⿳亠二口犬 consent, doctors have always been inclined (even after Salgo) to minimise the uncertainties about 'best' $\propto$ treatment. Moreover, they have also felt duty-bound to $\overrightarrow{\vec{O}}$ provide patients with an unequivocal recommendation 3 for action.

The new rules of the game defined in the SurgeonGeneral's memorandum gave rise to a paradoxical

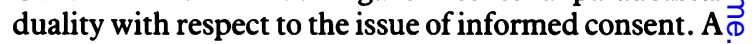
curious difference was now established between the clinical practice context (involving the overwhelmin:; majority of patients) and the research context (for aO relatively small number of patients)(1): in daily patient encounters, doctors were merely exhorted to solicito consent by an appeal to medical ethics or to legal self- $\rightarrow$ interest; in clinical research, investigators were now compelled by regulation to obtain informed consent.

IMMEDIATE IMPACT

One practical effect was immediate and dramatic: 옹 study-consent suddenly became a highly visible step in ${ }_{\sigma}^{\omega}$ the planning of all clinical studies - most particularly, in the design of controlled clinical trials. Unlike the laissez faire policy which characterised daily medical ${ }_{\stackrel{\Phi}{~}}$ experience, study-consent was now reviewed ${ }^{+}$ prospectively and it quickly moved to centre stage in respect of concerns about the conduct of studies.

\section{RESPECT FOR PATIENT AUTONOMY}

The arrival of study-consent in 1966 struck down $\frac{\circ}{\sigma}$ doctors' arguments based on a beneficence model to justify the broad limits of their authority in clinicalo research. The underlying, and indeed the controlling, idea of the new dictum in formal clinical studies waso one of respect for patients' autonomy. Now that the $\stackrel{?}{?}$ 
study-consent policy has been in place for more than 20 years, how can we judge the success of the innovation?

\section{RESPONSE TO PUBLIC CONCERN}

First, we need to remember that the 1966 directive of the American Surgeon-General was political. It was made in response to a public uproar after news reports revealed that, in an exploratory study of immunity to cancer, researchers injected live malignant cells into a number of elderly patients without obtaining their permission (10). Public concern was reinforced by Beecher's widely read paper published in June 1966 (11). He charged that clinical researchers were endangering the health and the lives of their research subjects (often prisoners, soldiers, and the mentally retarded) without informing them of risks or obtaining their permission. Twenty-two examples of the purported abuses were cited; they occurred, it was alleged, in the years 1950-65.

\section{HEDGING STRATEGY LIMITS RISK}

Beecher's assessment of the extent of maltreatment in clinical studies has been debated for years (12). It is worth noting that the new requirement of formal study-consent was not put in place in the United States because of any questions about unwarranted hazards to patients - potential or tangible - that were uncovered in treatment trials using randomised control design. Prior to 1966 there were, in fact, encouraging signs that the hedging strategy of random allocation provided important safeguards: hoped-for benefits and unanticipated risks were distributed equitably. Additionally, the design had the potential for reducing the numbers of injured in therapeutic disasters. Experiences in a number of neonatal clinical trials provided concrete examples to support the risklimiting argument (13). Moreover, the lessons were timely: by 1966, it was evident that unexpected disasters were occurring with alarming regularity as powerful new weapons were added to medicine's armamentarium.

\section{Nature and magnitude of risks}

Ten years after declaration of the study-consent dictum, a task force of the National Institutes of Health reported the results of the first systematic effort to obtain an estimate of the nature and magnitude of risks for human subjects enrolled in clinical research (14). In therapeutic trials conducted by 538 researchers who had studied 39,216 patients, the survey analysts found no indication that the risks were any greater than are encountered when treatments are given in other medical settings. (Most of the research-related deaths and injuries occurred in connection with the use of chemotherapy in cancer patients.)

\section{'EFFICACY' OF STUDY-CONSENT?}

More than two decades after the arrival of formal study-consent, it is discouraging to see that so little objective evidence has been collected concerning what might be called the 'efficacy' of the new dogma. From the very outset, and without let-up, questions have been raised about whether it is ever possible to determine if trial participants, or their surrogates, have been fully informed, and if they have given true consent.

The stipulation that consent for enrolment must be in writing has presented very little difficulty. However, there is a strong suspicion that it is virtually impossible to comply fully with the intent of the rule. What should, or can be done to determine with any certainty whether or not participants understand the full implications of what they have been told in a disclosure ritual? As compared with pre-1966, has study-consent succeeded in providing more protection for enrolled patients? Has the new understanding resulted in increased respect for patients' autonomy, and, as a practical consequence, has there been a change in the power relations between doctors and patients in the past two decades?

A wide range of opinion concerning these questions has been expressed in a flood of letters to editors, news reports, editorials, articles and books. At a consensus conference on controlled clinical trials, more than fourfifths $(79 / 92)$ of the respondents indicated that the obtaining of informed consent is problematic because patients (or surrogates) do not fully understand the implications of a formal clinical trial (15). One neonatologist said, very bluntly (and not for attribution!): 'I think informed consent is a farce.... The information [given to parents] is what I want it to be'. Some of this scepticism is supported by the findings in surveys of public opinion, but the evidence is weak and unique to the circumstances of a given study (16).

\section{DISCRETIONARY CONSENT FORMATS}

One randomised trial involving cancer patients was carried out in Australia; total disclosure was compared with a modified individual approach (17). Again, the results obtained in this trial cannot be generalised with any confidence. Moreover, the authors indicated that the issue could not be studied further - Australian rules requiring total disclosure and written consent can no longer be waived.

Alternative approaches have been proposed (for example inform only patients allotted to the experimental arm of a trial (18), a process model of informed consent based on the assumption that medical decision-making is a continuous process (19)) but institutional review boards have been reluctant to allow any departures from inflexible regulations. It is hard to understand how it will be possible to determine the reasonable limits of the rigid informed consent ritual when it is declared by fiat to be irreproachable. In the United States, the status quo seems to have been effectively immunised against all criticism.

\section{AN AUTHENTICITY TEST}

A strange situation arises when patients who refuse to be enrolled in a controlled clinical trial ask for the new treatment outside of the context of the trial. Response to this request is a powerful test of what might be called the 'authenticity' of the trial. 
The sincerity of the statements made in the studyconsent ritual explaining the justification for the controlled trial is placed under a dark cloud if the request from a refuser is granted. A similar kind of confusion results from the therapeutic privilege claimed by doctors who refuse to participate in the trial and treat all eligible patients with the new treatment currently under test.

\section{THE PRE-CONDITION OF BALANCED DOUBT}

These difficulties remind us that there is always an ethical dilemma whenever a new treatment is proposed to replace the previous standard. It is a necessary condition when asking for participation in a planned trial of parallel treatments that the doctors be in a state of genuine uncertainty (the balanced doubt has been labelled 'equipoise' (20)). When doctors believe that patients in one arm of a planned trial are to be provided with better treatment, they usually disqualify themselves from participation. They argue that they cannot, in good faith, represent to patients that the treatment choices in the trial are equal. How can we resolve the apparently irresolvable conflict between the ethical requirement that a patient must always be offered the best treatment known, and the equivocal choice in a comparative trial? The formal exercise is carried out in the sincere hope that the newly-proposed treatment will surpass the accepted regimen.

\section{Deflation of individual preference}

The paralysing dilemma can be resolved if we can agree that the time has come to question the high moral status accorded an individual doctor's treatment preference. Particularly when that choice is backed by weak evidence. Personal and idiosyncratic decisions about 'best treatment known' cannot be defended, Freedman has recently pointed out, when there is an honest disagreement among the experts about the relative merits of treatment alternatives (21).

\section{Doubt by consensus}

The ethics of medical practice should grant no moral standing to treatment preference, no matter how strongly asserted, when that opinion is based on anything less than evidence presented publicly and convincingly to the clinical community. Good medicine, Freedman reminds us, is defined, not by individual doctors, but rather by professional consensus.

\section{Disclosure of uncertainty}

It follows from these arguments that a doctor with a decided treatment preference may, in good conscience, participate in a controlled trial when he/she acknowledges that there is insufficient evidence to judge 'best treatment', and when that state of doubt is disclosed to patients.

\section{PROTECTION OF REFUSERS}

It also follows that, for their own protection, only the standard treatment should be available to eligible patients who refuse to enrol in a formal trial. It is irresponsible, I argue, to release the untested treatment without the protection available in the hedging strategy of a controlled trial. Trial participants are provided with the fairest kind of protection that can be devised against unknown hazards. Since the nature and the size of such risks are unknowable in advance, the fate of each individual is placed in the hands of the goddess of chance (as it is in everyday life whenever we step into the unknown).

Ample support for a policy banning use of new treatments outside of the context of a controlled trial is provided by the experience of the recurrent disasters that have taken place in the past few decades. The most dramatic explication of the issues is provided by the experience with the use of DES (diethylstilbestrol) to improve pregnancy outcome (22). As it turned out, only the offspring of pregnant women in trials with concurrent controls received an equal chance to reap the hoped-for benefit or to be shielded from a completely unexpected risk (alarming numbers of the daughters born to DES-treated women developed a rare type of vaginal cancer decades after birth). Although several controlled clinical trials were unable to demonstrate efficacy of treatment, during a ten-year period between 1960 and 1970, an average of 100,000 prescriptions for DES were written each year in the US, outside the context of formal clinical trials, for women who were pregnant (23). It is worth remembering the fortuitous benefit of trial participation enjoyed by women whose mothers were allotted to control groups (no DES given) in the early controlled trials. These fortunate unexposed individuals have been spared the increased cancer risk (and reproductive disturbances) hanging over the lives of hundreds of thousands of American women.

\section{JUSTICE IN CLINICAL TRIALS}

The moral principle of justice is tested in the presentday study-consent requirement in clinical trials. Clinical studies in the past have been conducted more 3 frequently among impoverished minorities than among the privileged American classes. The poor were enrolled as subjects in medical investigations because it 0 was convenient (researchers were located in the teaching hospitals used by poor patients), and because of gross insensitivity to the unfairness of the custom.

An American commission has advised that children $N$ who participate in research projects should be selected $N$ so that the burdens of participation are distributed $\underset{\mathrm{N}}{\mathrm{N}}$ justly - that is, among all segments of society (24). The $O$ recommendation is painfully silent about how this just standard is to be achieved in practice.

\section{Unequal representation}

In clinical trials, we depend on those who give consent $T$ freely (25). The approach thwarts the basic principles

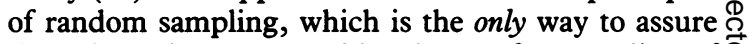
that there is a reasonable chance for equality of $\stackrel{\mathbb{Q}}{\propto}$ representation across all social classes. It is very unlikely, I suspect, that conscription by lottery will be used in any country to guarantee that there will be nosocial inequities.

Social filter effect?

Nonetheless, we should be ready to question anything 
done in the recruitment of patients for study that would seem to exaggerate inequalities (26). Is it possible, for example, that the study-consent procedure itself functions as an effective social filter? Does it select out, for refusal, those on the upper rungs of the social ladder, the least 'captive' members of the community, those most likely to understand what is requested in the consent ritual? Among consenters, is there disproportionate representation of those who do not understand, those too frightened to refuse, those who are socially disadvantaged?

\section{Informed consent in the future}

I have no doubt that the debates concerning informed consent will (and should!) continue unabated. It has been impossible, in the first two decades of studyconsent, to devise practices that satisfy the competing moral imperatives of respect for autonomy, concern for beneficence with emphasis on the value of health, and a vigil for justice. It has been said, that the current doctrine and set of practices compromise all values and satisfy none in their entirety - as a result, there is endless squabbling (19). I will be very surprised if we are able to find formats that will satisfy patients and their families, doctors, legal experts, bioethicists, and the community at large. So long as the arguments remain heavily freighted with opinion and so weakly challenged by concrete evidence, the outlook for progress seems dim.

\section{NEED FOR COMPARATIVE STUDIES}

A way must be found, I suggest, to experiment with various discretionary approaches that would strike a realistic balance among the competing interests. We need an approach that would conserve the spirit of informed consent without snuffing out the flame of responsible clinical study.

The double standard vis-a-vis daily-consent and study-consent will continue so long as we are unable to come to some agreement about the outcomes of importance that will permit a measured comparison of alternatives. At the controlled trial consensus conference convened in 1984, three-quarters of the conferees (70/93) agreed with the statement: 'There should be no fundamental difference between the information given to a patient in order to obtain informed consent in a controlled clinical trial and that given to a patient in daily practice' (15). The opinion is not very helpful, I repeat, unless it leads to comparative studies designed to measure the consequences of merging daily-consent and studyconsent in the real world.

\section{Author's note}

Portions of this paper, in different form, were presented to the Southern Society for Pediatric Research, Annual Meeting, February 5, 1988, New Orleans, Louisiana; these are published in the American fournal of Medical Sciences (5).
William A Silverman, MD is Professor of Pediatrics (Retired), College of Physicians and Surgeons, Columbia University.

\section{References}

(1) Pernick M S. The patient's role in medical decision making. A social history of informed consent. In: President's Commission for the Study of Ethical Problems. Making health policy decisions. Washington: Government Printing Office, 1982.

(2) Slater v Baker and Stapleton, 95 Eng Rep 860 (K B 1767)

(3) Percival T. Medical ethics; or code of institutes and precepts, adapted to the professional conduct of physicians and surgeons. Manchester: S Russell, 1803.

(4) Faden R, Beauchamp T L. A history and theory of informed consent. New York: Oxford University Press, 1986.

(5) Silverman W A. Consent for experimentation involving neonates. American journal of medical sciences 1988; 296:354-359.

(6) Salgo $\mathrm{v}$ Leland Stanford Jr University Board of Trustees, 317 P 2d 170 (Cal Dist Ct App 1957).

(7) Katz J. The silent world of doctor and patient. New York: The Free Press, 1982.

(8) Harris L et al. View of informed consent and decision making. Parallel surveys of physicians and the public. In: President's Commission for the Study of Ethical Problems. Making health policy decisions. Washington: Government Printing Office, 1982.

(9) Stewart W H, Surgeon-General. Clinical investigations using human beings. Memorandum dated February 8, 1966.

(10) Katz J. Experimentation with human beings. New York: Russell Sage Foundation, 1972.

(11) Beecher H. Ethics and clinical research. New England journal of medicine 1966; 274:1354-1360.

(12) Rothman D J. Ethics and human experimentation. Henry Beecher revisited. New England journal of medicine 1987; 317:1195-1199.

(13) Silverman W A. Retrolental fibroplasia: a modern parable. New York: Grune and Stratton, 1980.

(14) Cardon P V, Dommel F W Jr, Trumble R R. Injuries to research subjects: a survey of investigators. New England journal of medicine 1976; 295:650-654.

(15) Blum A L, Chalmers T C, Deutsch J et al. The Lugano Statement on controlled clinical trials. Foumal of international medical research 1987; 15:2-22.

(16) King J. Informed Consent. Institute of Medical Ethics bulletin. Supplement no 3. London: IME Publications Ltd, 1986, Dec.

(17) Simes R J, Tattersal M H N, Coates A S et al. Randomised comparison of procedures for obtaining informed consent in clinical trials of treatment for cancer. British medical journal 1986; 293:1065-1068.

(18) Zelen M. A new design for randomised clinical trials. New England journal of medicine 1979; 300:1242-1245.

(19) Applebaum P S, Lidz C W, Meisel A. Informed consent: legal theory and clinical practice. New York: Oxford University Press, 1987.

(20) Fried C. Medical experimentation: personal integrity and social policy. Amsterdam: North Holland Publishing Co, 1974.

(21) Freedman B. Equipoise and the ethics of clinical research. New England journal of medicine 1987; 317:141-145. 
(22) Herbst A L, Ulfeder H, Poskanzer D C. Adenocarcinoma of the vagina: association of maternal stilbestrol with tumour appearance in young women. New England journal of medicine $1971 ; 284: 878-881$.

(23) Heinonen O P. Diethylstilbestrol in pregnancy. Cancer $1973 ; 31: 573-577$.

(24) National Commission for the Protection of Human Subjects of Biomedical and Behavioural Research.
Research involving children: report and recommendation. Document No (OS) 77-0004 Washington: Government Printing Office, 1977.

(25) Kauffman C L. Informed consent and patient decision making: two decades of research. Social science and medicine 1983; 17:1657-1664.

(26) Edlund M J, Craig T J, Richardson M A. Informed consent as a form of volunteer bias. American journal of psychiatry 1985; 142:624-627.

\section{(Continued from page 5)}

practice and in clinical trials. Fournal of medical ethics $1989 ; 15: 6-11$.

(2) Chalmers I, Baum M. Consent to randomised treatment [letter]. Lancet 1982; ii:1051.

(3) Mason J K, McCall Smith R A. Law and medical ethics (2nd ed). London: Butterworths, 1987: 152-159.
(4) Sidaway v Board of Governors of the Bethlem Royal Hospital; [1985] 1 All ER 643, HL.

(5) Anonymous. Adequately informed consent [editorial] fournal of medical ethics 1985; 11:115-116.

(6) Declaration of Helsinki. In: British Medical Association The handbook of medical ethics. London: BMA Publications, 1984: 73-76. 